\title{
UN PROBLEMA DE PROYECCIÓN DEL LÉXICO EN ESTRUCTURAS SINTÁCTICAS: LA POSICIÓN DEL ADJETIVO ADJUNTO EN ESPAÑOL
}

\author{
JULIO CALVO PÉREZ \\ (Universidad de Valencia)
}

\section{PRIMERA PARTE}

Tanto la gramática tradiciónal como las nuevas metodologías lingüísticas se han sopesado a veces con el test de un espinoso problema: el de la posición del adjetivo. Hoy, con una perspectiva distinta emanada de la Topología lingüística ${ }^{1}$ se puede, o al menos esa es nuestra pretensión, arrojar nueva luz sobre los viejos problemas, unificando armónicamente las soluciones pretéritas tras su discusión en profundidad.

\section{Propuestas de la gramática tradicional}

Refiriéndonos únicamente al español ${ }^{2}$ cabe destacar en primer lugar la opinión de Bello (1981) que adopta la dicotomía especificativo/explicativo según haya restricción (los animales mansos) o no (las mansas ovejas) de la extensión del sustantivo. Sin que sea una norma absoluta acepta - $\$ 48$ - que los adjetivos en posposición generalmente especifican. Pero esta intuición, contra la opinión del propio Bello, no sólo registra excepciones en la poesía: los buenos alumnos aprueban siempre, etc.

Por su parte Salvá (1852) mucho más ecléctico, acepta hasta cuatro argumentos de interés: a) el adjetivo señala una cualidad propia o esencial (amarga adelfa) vs accidental o especificativa (marinero francés, vino agrio), b) la anteposición se emplea para los usos figurados (una buena alhaja = «un pícaro»), c) el orden es fijo en las frases hechas o fosilizadas (El Espíritu Santo/Los Santos Lugares), d) por nece-

1 Cfr. Calvo (1985), que desde ahora abreviaré como PL.

2 Las propuestas han sido muy diversas en todas las lenguas románicas. Cfr. Reiner (1968) para el francés, Sciarone (1970) para el italiano, etc. 
sidades rítmicas el adjetivo corto —opinión que comparte con Bello- suele anteceder al nombre (luz dorada/sol resplandeciente), etc.

Hanssen (1945) se fija especiaimente en el criterio dicotómico de objetividad/ subjetividad (un gran emperador, pero un gran hombre), aunque señala como excepción la posibilidad de la posposición subjetiva (dinero malo).

Gili Gaya (1973) retomando la idea del comportamiento no estándar del adjetivo en relación con la anteposición, señala que es el valor estilístico el que «rige permanentemente la colocación del adjetivo" (\$164). Tras aceptar con reparos la dicotomía de Bello, asume lo que Hanssen y posteriormente Lenz (1935) concretarian como objetividad psicológica. En tercer lugar acepta este mismo autor los argumentos rítmico-melódicos insinuados por Salvá y desarrollados con bastante amplitud por Fernández Ramírez (1950). Este se hace acreedor de la dicotomía orden atributivo para AS vs orden predicativo para SA, formulada anteriormente por $\mathrm{K}$. Bühler, pero no conforme con ella enuncia una serie de leyes estructurales y cuantitativas (recuérdese la sarta con $+(A r t)+A S / S A$ ) apoyándose para ello, por primera vez, en un corpus bastante exhaustivo. El «Esbozo...» (R.A.E., 1973), da como buenas las opiniones de Gili Gaya, así como las de S. Fernández Ramírez haciéndose eco, como éste, de la prescindibilidad del epíteto "ornans» (enjugarse la frenteenjugarse la húmeda frente) y de la capacidad rítmica polarizada (el eremítico pais del Bierzo) o geminada (sobre el alto y enhiesto cuello de la capa) cuando el atributo deja de ser, por su posición anterior, el miembro dominante de la frase que en castellano, como todos los autores reseñados están de acuerdo en afirmar, es de SA. Efectivamente, la función definitoria y restrictiva de SA (máquina calculadora) es, para estos autores, preferible comunicativamente a la envolvente o explicativa AS (mejor dulce miel que miel dulce).

Otros tratadistas generales sólo aportan confusión o eclecticismo a las clasificaciones anteriores. La distinción de (Marcos, 1980) entre epítetos libres (en los calurosos dias de Agosto, pero pueden ser "fríos" en B. Aires) y epítetos intrínsecos (la blanca nieve) no tiene en cuenta el necesario recurso a otros mundos posibles (podemos concebir el referente nieve como azul, rosada, etc.). En cuanto a AlcinaBlecua (1975) sólo se limitan a las dicotomías no originales de G. Sobejano (vago/ concreto - tomado de Gröber-, afectivo/intelectual, etc.) y las de Hanssen y A. Bello ya citadas.

Si nos atenemos a la transición al estructuralismo podría sopesarse también la opinión de Jespersen (1975) que centrándose, desde la lógica, en el nombre propio, observa la necesidad de posponer el adjetivo con artículo (Valencia la clara) pero anteponerlo obigatoriamente sin él (el católico Felipe). La razón se aprecia en el esquema siguiente:

Nombre común (clase) +Adjetivo (subclase)=subclase (especificativo)

Nombre común (individuo) + Adjetivo=individuo (explicativo)

Nombre propio (individuo)+Adjetivo=individuo (explicativo)

En relación con la pragmática, Jespersen señala que el sustantivo es más especializado y por tanto antecedente (Napoleón tercero). A pesar de su perspicacia, este argumento ha quedado superado ya. Desde el mismo plano del análisis de Jespersen, la posición en piedra/gris debería ser indiferente, ya que el número de cosas grises es empíricamente equiparable al número de piedras. En el caso de leche cuajada o caballo bayo la restricción de entornos de los adjetivos correspondientes 
es tal que siempre deberían ir antepuestos (es el caso en que la clase de sustantivos regentes es arbitraria como señala Stati (1973). Semejante precisión requeriría el orden en A) griegos pensadores/ B) pensadores griegos, cuya exigencia teórica seria: la mitad de posibiidades para griego y otras tantas para pensador, aunque no es tal el caso cuando se observa que $A \supset B$, pero BDA.

Con respecto a los argumentos que anteceden podría pensarse, sin salir de los propios esquemas mentales de la gramática tradicional, que una solución que jerarquizara las surtidas ofertas dicotómicas de estos autores podría dejarnos contentos a todos. En efecto, las soluciones, tomadas una a una, son fácilmente rebatibles. El argumento de la posición libre en los adjetivos explicativos, por ejemplo, queda condicionado a la sintaxis. Así: el vino dulcelel dulce vino, pero vino dulce en demasia/dulce en demasia vino. En tal caso, un adjetivo transitivo o transitivizado no puede aceptar la anteposición. Obsérvese que rojo vino sólo es posible con rojo 1 , pero no con rojo (=enrojecido): vino enrojecido con aditivos $\sim{ }^{*} \mathrm{rojo}_{2}$ vino.

La significación subj./obj. del adjetivo no depende quizás de la posición, sino de la asociación paritaria S-A. Por ello mi negra suerte/la suerte negra (R.A.E., 1973, «\$3.9.6.C») es tan subjetivo en el primer caso como en el segundo, del mismo modo que es total la objetividad en ejemplos como: el vestido negro/e/ negro vestido. Este argumento rechazaria de plano la opinión largamente mantenida sobre ejemplos como un vestido negro/negros presagios en que el sustantivo $/ \mathrm{Mat} /+\mathrm{el}$ adjetivo de color objetiva lo que sólo puede ser connotación con el sustantivo/-Mat/ en uno de los sumandos.

Otro argumento que queda exonerado fácilmente hace referencia a la hipotética libertad del adjetivo en la poesía. Aparte de modas que puedan hacer que el poeta se incline por AS, una vez elegido tal camino, no es posible la inversión sin romper el ritmo, la rima o ambas cosas a la vez. Así, en los versos de Alberti: jCuántas veces, oh Cádiz, te habré visto... sobre el óvalo azul de tu bahia, la anteposición de azul es imposible por más que en teoría se trate de un epíteto "ornans". La cacofonía en sobre el azul óvalo de tu bahía está justificada por la ruptura del ritmo mixto

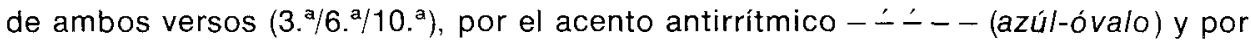
el aumento de una silaba en el $2 .^{\circ}$ verso. Esto es bastante frecuente en poesía donde la libertad en el orden es, en general, muy restringida: "texto como unidad".

Ateniéndose a la discusión sobre las estructuras con+Art+SA/AS de S. Fernández Ramirez, éste utiliza el argumento del orden rítmico de masas crecientes al observar que en el $100 \%$ de las apariciones la palabra más corta antecede a la más larga sea $S$. o A. Cuando el artículo es $\varnothing$ : con $+S A / A S$, en AS sólo se cumple la tendencia anterior en un $50 \%$ de los casos. Pero obsérvese que estos ejemplos son igualmente aceptables:

1) Un cometa, con una espléndida estela cruzó el sistema solar.

2) El/un poema, con una estructura libre, parece menos poema.

Obsérvese que en ambos casos es posible la paráfrasis con ser y no con estar: ía estela es/*está espléndida__la estructura es $/{ }^{*}$ está libre y lo inverso ocurre en:

3) ${ }^{*}$ El zagal, con (un) desabrochado puño, se dirigió hacia el légamo.

4) *La muchacha, con (una) rota espardeña, no podía caminar.

Donde sólo es posible la indicación de +Result., sin que aparezca +Proc.: el puño 
está desabrochado/la espardeña está rota ${ }^{3}$. Pero si nos atenemos a ejemplos como:

5) (Periódico) con suplemento semanal (EL PAIS, p. 1).

6) ...con un ahogado sofoco (V. Aleixandre "Historia del Corazón").

7) ...contribuir con una proporción adecuada a las necesidades financieras (EL PAIS, 12-4-80, p. 6).

8) Se come mucho con huevos fritos (EL PAIS, id. p. 29).

Se observará que 5) no admite la anteposición, porque SつSA (adj. determinativo), a pesar de el suplemento es/está semanal. 8), por la misma razón semántica, es inamovible, pero los huevos ${ }^{\star}$ son/están fritos (adj.). 6) es poético, inamovible, aunque el sofoco es/está ahogado y 7) también por tratarse de un adjetivo complementado, por más que registre idénticas posibilidades parafrásticas.

1.1. Pues bien, los escrutinios anteriores nos permiten enunciar la siguiente ley de posición: SON LOS FACTORES SEMÁNTICOS LOS QUE MARCAN CUÁL DEBE SER LA POSICIÓN DEL ADJETIVO ADJUNTO AL SUSTANTIVO. De ella se desprenden los siguientes corolarios:

$\left.1{ }^{\circ}\right)$ La posición del adjetivo será siempre $S+E$ cuando el adjetivo señala el resultado de un proceso y sin señalarlo si forma unidad semántica con el sustantivo al que determina (guardia civil).

$\left.2 .{ }^{\circ}\right)$ La no aparición de los rasgos semánticos/+Result./, /+Determ./ posibilita la movilidad del orden $\mathrm{S} / \mathrm{A}$, a no ser que incidan factores rítmicos o sintácticos que inmovilicen en segunda instancia la estructura.

$\left.3 .^{\circ}\right)$ Si los corolarios 1) y 2) no se cumplen puede intervenir un tercer orden de restricciones a la estructura S/A producidas por tendencias cuantitativas crecientes o por la equilibrada distribución de masas en la prosa (la madrileña calle de Toledo).

4. $\left.{ }^{\circ}\right)$ Las frases hechas deben su existencia a factores diacrónicos distintos de los que se han analizado (querida Ana).

\section{El estructuralismo europeo inicial}

A pesar de los resultados parciales de 1.1. conviene discutir sucintamente opiniones que lleven el sello definido de una escuela. Bally (1965), por ejemplo, relaciona el problema de la posición con el E. y el R. del mensaje de manera que vertido hacia el primero se da la anteposición sintética (la redonda tierra), pero orientado al segundo, la posposición analítica (la tierra (es) redonda), lo que propicia la solución subjetivo-apreciativa para AS, acompañada incluso de un cierto énfasis (Cfr. una FORmidable explosión). Por otro lado (Bally, 1965, «\$363») señala que "L'adjectif antéposé a parfois un sens voisin de celui d'un déterminatif ou d'un quantificateur dont il occupe la place" (le même roi $\cong$ le roilel mismísimo rey $\cong$ el rey/lpetite maison $\cong$ maisonnette/una pequeña casa $\cong$ una casita). Esta misma tesis es la que sostiene Weinrich (1966). Pero estos comentarios necesitan un mejor ajuste. La

3 Previamente, como señala López García (1983), estar ha rellenado el nudo sintáctico, por la razón de que, a excepción de ser (Proceso puro), todos los verbos se bifurcan en Proceso tResultado. 
posposición puede no sólo enfatizar fónicamente (una explosión FORmidable), sino adoptar el mismo mecanismo reductivo (una casa pequeña $\cong$ una casita). Lo que no es obstáculo para que se reconozca que distribucionalmente hablando el adjetivo antepuesto llega a parecerse a otros determinantes que se ubican próximos a él. No obstante, como señala Stiehm (1975), el orden secuencial depende de una convención progresiva de contraste a complejidad dentro del orden libre AS/SA, que el español tiene, de modo que no es posible aceptar que un paradigma tan limitado como el del artículo tenga un estatus similar al del número indefinido de adjetivos que admiten anteposición. Tampoco es muy fiable el argumento que opone AS/SA a morfema y lexema respectivamente ${ }^{4}$, ya que se basa en que el morfema es más vago y reducido en intensión y se bifurca en paradigmas naturales como los que se encuentran en los adjetivos (grande/pequeño, bello/feo, etc.). Este argumento es falaz porque precisamente la dicotomización antonímica permite la mayor especificación y ésta suele darse casi exclusivamente, como señalara Bello, en la posposición. Según ello, también los pares blanco/negro o ascendido/degradado serian también morfemas, pero como critica adecuadamente Sciarone (1967) ni eso es posible ni existe distribución complementaria en los usos (un gran charco/un charco grande). Es más, muchas veces es incluso imposible la anteposición: la nieve blancalla blanca nieve, pero el hombre de raza blanca/*de blanca raza//Este es un soldado degradado/*un degradado soldado, etc.

\section{El funcionalismo praguense}

El funcionalismo praguense más centrado en un enfoque psicológico que lógico de la lengua admite que el orden de las palabras se debe más bien a dicotomías como lo conocido/lo nuevo, lo que antecede/lo que sigue, etc., que se suelen definir genéricamente como tema/rema. Pero antes de pasar a referirse al par de conceptos citados que, por cierto, no han sido ejemplificados sobre el ajetivo que sepamos, conviene aludir al hecho de que toda especificación funcional SA ha de hacerse hasta conseguir una referencia válida (traje $\rightarrow$ el traje $\rightarrow$ el traje nuevo $\rightarrow$ el traje nuevo de papá...), siendo la atribución AS el mecanismo anafórico que remite a un contexto anterior, sin que necesariamente SA lo haga a lo posterior ${ }^{5}$. Siguiendo $A$. López García es necesario mantener AS/SA en un nivel fraseológico, relacionado, aunque distinto, con el nivel oracional. Esto debe ser así a causa de una multiplicidad de hechos de derivación ${ }^{6}$ o referencia ${ }^{7}$ y a la imposibilidad parafrástica de ejemplos como el calor solar ${ }^{*}$ el calor es solar $/ / m i$ actual casa ${ }^{*} m i$ casa es actual, etc.

Con esta restricción es posible abordar el tema de la posición del adjetivo adjunto en español, estableciendo una jerarquía entre las dicotomías praguenses a las que hemos hecho referencia. Más ampliamente, si llamamos $\alpha$ a lo conocido y $\beta$ a lo

4 Cir. Weinrich (1966: 85) que, como se comprobará, está muy próximo al de Bally (1965) y a una larga tradición de autores que se mueven en este terreno.

5 Cfr. esta misma opinión en López García (1980:: 148-151).

6 Cfr. Nevi (1973: 332-345) y Luján (1980), entre otros muchos generativistas de similar opinión.

7 Crr. Bolinger, (1967: 1-34) que desarrolló con bastante clarividencia esta cuestión. 
dependiente del contexto, $\alpha$ incuye a $\beta\left(\alpha \supset{ }^{\prime} \beta\right)$, ya que lo conocido puede no haber sido dado en el texto con anterioridad. Según ello, $\alpha$ equivale a la predicación oculta de Svoboda en la que aparece la relación "conocida» $A+S$. $\beta$ define a AS cuando la relación es conocida y dependiente del propio texto (contexto inmediato). A su vez, lo conocido y no dependiente al mismo tiempo $(\alpha \cap \bar{\beta})$ debe referir al adjetivo adjunto pospuesto: atribución conocida por experiencia (contexto mediato). En este orden de cosas, $\alpha$ puede considerarse como predicación explícita en relación a lo conocido, o sea, tema en un sentido lato, y $\beta$ como rema con una capacidad creciente de dinamismo comunicativo. Desde este punto de vista del FSP («funcional sentence perspective") la frase AS o SA puede hallarse ubicada en el sujeto o en el predicado psicológico de la oración: $\gamma / \bar{\gamma}$. Si, como es lógico, puede existir una enfatización que incida sobre los valores presupositivos de la oración, debemos asumir también $\delta / \bar{\delta}$ o dicotomía tópico/comentario ${ }^{8}$, que representa a $\delta$ como una estructura no focal que recubre la doble experiencia del E. y el R. y a $\bar{\delta}$ como un foco cuya presuposición es igualmente exterior a la oración. Así (Palková-Palek, 1978), se llega a aproximar $\delta$, a $\alpha, \beta$ y $\gamma$ en cuanto a presuposición se refiere, y además es posible idear $\varepsilon$ (énfasis) en relación con $\alpha$ y $\gamma$, es decir, en cuanto a foco marcado vs no marcado. Como se comprenderá, la presencia de un rema $(\varepsilon)$ entre elementos temáticos adjuntos excluye automáticamente la presencia de $\delta$ ( $\bar{\varepsilon}$ o rema en la parte final de la oración, cuando el orden de las palabras y la pronunciación son los más neutros posibles) ${ }^{9}$.

A la vista de todo ello resulta instructivo representar esquemáticamente cuál es la posición fraseológica del adjetivo, pero sin perder el hilo de la estructura lineal de la oración, a tenor de la filosofía que emana de la E. de P. He aquí unos ejemplos y sus representaciones:

\section{$\alpha \quad \beta \quad \gamma \quad \delta \quad \varepsilon \quad$ Marca}
a) Me gustan los dulces pasteles de crema
b) Las suaves ondulaciones del terreno no nos molestan
c) Me gustan más los pasteles dulces que los salados
d) Los pasteles duices están sobre el anaquel
e) Los pasteles DULCES están sobre el anaquel
f) Yo hablé de las HERMOSAS caras, no de las feas
g) Los alumnos, despistados, respondían a su aire
h) ¡Magnífico piso!

\begin{tabular}{|c|c|c|c|c|}
\hline+ & $t$ & + & - & \\
\hline$\dashv-$ & + & - & + & \\
\hline+ & - & + & - & \\
\hline+ & - & - & + & \\
\hline+ & - & + & + & \\
\hline+ & - & - & + & \\
\hline & - & \pm & $(-) \pm$ & \\
\hline & -1 & + & + & \\
\hline
\end{tabular}

No se apuran aquí todas las posibilidades teóricas, pero hay suficiente material para intuir de qué modo puede enfocarse la estructura S-A desde una perspectiva funcional. Los dos últimos ejemplos se marcan con $\left(^{*}\right)$ para señalar su carácter fronterizo. La $1 .^{a}$,

8 Palková-Palek, (1978: 212-227), Sgall (1972: 1-14) entre otros muchos autores de el $E$. de P.

9 Cfr. un desarrollo minucioso de estas cuestiones en Halliday (1967: 37-81 y 199-244; Halliday, 1968: 179-215). 
por la relación de despistados con el adverbio apositivo (Meier, 1948) sería una oración simple, pero desde la perspectiva transformacional parece más conveniente considerar el ejemplo como bioracional: Los alumnos [Ios alumnos (QUE) estaban despistados] respondian a su aire. La última porque hay razones igualmente de peso para aceptar la solución oracional (Benveniste, 1966) o rechazarla (Hjelmslev, 1972). Por otro lado, se parte de la idea de que toda anteposición es marcada $(33 \%)$ con respecto a la posposición $(67 \%)$. Además, el orden o la entonación no neutrales son indicativos igualmente de marca. En términos semánticos, sin embargo, las dificultades aumentan, porque si aceptamos como válida, por ejemplo la clasificación de los adjetivos en calificativos y relacionales (Bartoš, 1978), y asumimos la posición fija SA para los últimos de la doble SA/AS para los primeros en consonancia con el enfoque teórico de Jakobson (1975), veremos que el orden SA es marcado para la restricción (planta umbelifera ${ }^{*}$ umbelifera planta, pero noche fria/fría noche), mas a su vez AS es marcado para la no restricción (los dulces (-restric.) pasteles//los pasteles dulces/navideños (+restric.)) con lo cual el problema se trasplanta a si deben o no diseñarse las marcas positiva o negativamente, o si la dinámica de la lengua exige hacerlo de ambos modos a la par (Cfr. IOS NAVIDEÑOS pasteles, donde AS es marcado para la restricción de la no restricción, etc.).

\section{La posición del adjetivo en la psicomecánica}

Para la psicomecánica el tratamiento del tema que nos ocupa es marginal (Guillaume, 1971). Éste distingue entre une vraie femme y une femme vrai y afirma que en el primer caso se trata de alargar la inmanencia del proceso de sustantivación y en el segundo la trascendencia (una mujer verdadera, verídica, pero una verdadera mujer, una mujer que es verdaderamente tal). Este mismo argumento, con un adjetivo modificador de referente, no de referencia (Bolinger, 1967), debería plantearse de otro modo, como es lógico; además, imputar al adjetivo los mismos procesos de extensión o cierre que al artículo no deja de ser chocante (Guillaume, 1971, 1973). Pottier, por su parte, tras señalar que AS es integrado y presenta unidad y SA es no-integrado o dual (Pottier, 1968), observa la relación entre la modificación del lexema (un BUVeur gros) y la del morfema (un gros buvEUR). Sin embargo, tal cosa no puede ser aceptada, pues si se admite la interpretación él bebe mucholél es gordo, también debería hacerse lo mismo en un buen jugador (él juega bien)/un jugador bueno (él es bueno), pero esto no es en general posible. La opinión, en fin (Lamíquiz, 1975) de que AS tiende a la lexicalización sólo puede admitirse parcialmente porque si un triste salario representa un orden fijado, aún más lo representan balarrasa/malasombra, etc., ya definitivamente soldados (frente a perra gorda por ej.), lo que nos aconseja ir con cuidado en estos temas en que al núcleo de hoy se opone la periferia de otros estudios de la lengua. 


\section{La posición del adjetivo en la escuela de Copenhague}

La glosemática señala una doble relación entre adjetivo adjunto y sustantivo de modo que éste exige la concordancia con aquél, pero es exigido por él en calidad de categoria secundaria como ya señaló Jespersen (1975) y lo han hecho otros (Martinet, 1978; Alarcos, 1970; López García, 1983b, etc.). Este aspecto, que puede parecer marginal con respecto al enfoque semántico que se quiere dar al tema, engrana, sin embargo, con un problema que se plantea vigorosamente la PL (Calvo, 1985) y que se formula en términos de compatibilidad, pero se decanta en términos de concordancia intralingüística (ver más adelante). Aun así, las categorías abstractas en que se formula la $P L$ se ven trasladadas semánticamente cuando se impone un orden lineal en la frase. Por ello, como señaló extensamente Tesnière (1966), la concordancia no basta, imponiéndose entonces un orden que en español coincida generalmente con SA: un viejo filósofolun filósofo viejo/lun loco americano/un americano loco, etc.

\section{El adjetivo en el distribucionalismo}

El distribucionalismo da un avance gigantesco en el tema de la posición del adjetivo, sobre todo al alcanzarse su perfeccionamiento con la técnica de análisis por C. I. con Z. S. Harris (1951). Ya Bloomfield (1933) daba las bases teóricas al considerar que es posible la expansión de fresh milk a good, sweet, fresh milk, etc., pero que al ubicarse ante el sustantivo el adjetivo limitante this: this milk se quiebra el desarrollo de la expansión por la izquierda (: good this milk) para ciertos adjetivos, aunque sea el envolvente all quien pueda cerrar el proceso (all this fresh milk), etc. Posteriormente Vendler (1968) en un memorable trabajo conseguia, por este procedimiento, establecer nuevas clases de adjetivos en inglés, la primera de las cuales se subdivide aún en una veintena de posibilidades.

Aplicado al español, es digno de mención el artículo de Ringo (1954) que desarrolla las ideas bloomfieldianas destacando las siguientes categorias:

a) Adjetivos unidos al sustantivo en posición fija o adjetivo l: libros franceses.

b) Adjetivos unidos al sustantivo en anteposición inmediata, pero que se pospone al grupo formado por $\mathrm{S}+\mathrm{A}_{\mathbf{1}}{ }^{10}$ : (magnificos) libros franceses (magnificos).

c) Adjetivos limitantes que preceden a la cadena $A+S$ : cierto vago aire.

d) Adjetivos definidores que preceden a la clase c): esas dos infelices mujeres.

e) Adj. todo que preceden a todos los demás.

El resultado del trabajo de Ringo, con ser aceptable, revela carencias importantes, no sólo por la crítica de Slmón (1979) de que las listas de adjetivos I y II que proporciona son inexactas, sino porque a la traslación intraadjetiva por acento contrastivo (Luján, 1980), hay que añadir fenómenos importantes que $E$. Ringo no analiza. Así, por ejemplo, los adjetivos limitantes y definidores también se posponen: no tenía defecto físico alguno/era enemigo acérrimo mio, etc., incluso lo hace todo: en la ciudad toda de Bhopal reina el horror de la desgracia. Aparte de ello, las clases

10 Cfr. al respecto el desarrollo del tema en Sciarone (1970) y el magnífico estudio de Rojo (1975). 
entre sí se superponen (tantas otras cosas/otras tantas cosas) o se recategorizan (extranjero millonario/millonario extranjero), etc. Veinte años después (Stiehm, 1975), haciendo uso de los conceptos sausureanos de sintagma y paradigma, adecuadamente modificados por los de complejidad y contraste, da una explicación más coherente del orden libre detectado más arriba. Al comienzo de la cadena el potencial paradigmático es menor y más contrastivo (clases cerradas: artículo, etc.). Hacia el centro el paradigma crece y la complejidad aumenta (adjetivos, nombres...). Esta descripción se asocia con la sintagmática: cuando un elemento $E_{n+1}$ sigue a otro $E_{n}$ el contraste es similar al de los paradigmas iniciales — de más o menos-, pero si el elemento antecede y es no contrastivo (un sust. por ej.) su complejidad es máxima (elementos siguientes poco fáciles de prever -p. 69-). Este aspecto serviria de por si para explicar el orden AS/SA (bastante dinero/dinero bastante) y la intersección entre las clases (p. 64). En efecto, el contraste sintagmático en los elementos antepuestos y pospuestos del sintagma es similar en grado de distinción al contraste paradigmático asociado a las clases de origen (Cfr. todo en todo el mundo (máximo contraste, valor distintivo) igual que alemana en la antigua piedad alemana/nuevas en nuevas campañas militares en el Oriente Medio (menor distinción del elemento inicial) como grandes en todas aquellas mismas grandes (preocupaciones) (núcleo o casi núcleo: sutilidad de diferenciación paradigmática)). Así pues, al ser A modificador y $S$ núcleo en SA se intensifica el contraste (muchachas bellas: $S \supset S A$ ), pero en $A S$ se atenúa (bellas muchachas).

A pesar de los esfuerzos por lograr una mayor claridad de significado el distribucionalismo tropieza una y otra vez con sus propios laberínticos planteamientos. En ello confluyen varios problemas: el más grave, desde el punto de vista sintáctico, es considerar en una sola estructura todo el orden lineal cuando es necesario establecer varios de ellos para que los adjetivos limitantes, definidores, etc., se ubiquen en otras estructuras del sintagma como demuestra espléndidamente López García (1980). Aunque tales adjetivos estén aparentemente próximos entre sí, pertenecen, en definitiva, a otra dimensión.

Otro problema quizá aún más dramático es el de la semántica. Al estar desprovisto el distribucionalismo de capacidad para discernir la polisemia -aunque da un paso de gigante con respecto a la sinonimia (Bloomfield, 1933, 168)-el intento de explicación del significado por las "ocurrencias" de cada palabra en los entornos del sintagma es siempre un callejón sin salida. En esto radica, por ejemplo, el desesperado intento de $Z$. Vendler por acomodar a un espacio adjetivos como viejo, pequeño, etc. Las mismas objeciones deben hacerse sin duda a Hockett (1971) cuando clasifica los adjetivos según puedan ser sólo a): atributos de sustantivo (bueno), b): de sustantivo y verbo (mejor) o c): de sustantivo, verbo y adjetivo (bien) con lo que se llega a la curiosa paradoja que se deduce de esta ejemplificación.

En tercer lugar, si la sistémica ha conseguido superar la mera distribución por entornos, en las matrices ideadas por Harris, permitiendo que cualquier sintagma tenga en cuenta todas las elecciones posibles, es decir, convirtiendo el paradigma ausente en una opción libre actualizada en la que se «elige" y no sólo se «erige» una cadena (Halliday, 1967-1968), también aquí se tropieza una vez más con el muro ineludible del significado. ¿Quién puede sospechar que en el paradigma de joven por ejemplo (un chico joven) hay que desechar precisamente posibilidades como viejo, anciano, etc. ( ${ }^{*} u n$ chico anciano)? Se nos objetará que la elección debe 
hacerse sobre la totalidad del sintagma y esto es cierto, pero no por ello los problemas dejan de trasladarse también a éste. Compréndase, si no, que los problemas de segmentación o modificación de la amplitud del sintagma ya podrian estar resueltos, pero no lo están: Un coche nuevo $\rightarrow$ un/coche nuevo $\rightarrow$ un/coche//nuevo, pero coche $\rightarrow$ coche nuevo $\rightarrow$ un coche nuevo son igualmente permisibles a pesar de *coche nuevo ha adelantado al viejo; o las despedidas rápidas son las mejores $\rightarrow$ las despedidas son las mejores, etc.

6.1. Una corriente del distribucionalismo prefiere centrar sus investigaciones en la Ilamada teoría de valencias. Esta se origina en Bull (1954), y apunta ya hacia una solución que el estructuralismo más ortodoxo de Wells o Harris no había previsto. En efecto, la interpretación de las tres primeras páginas ( $\neq$ las primeras tres páginas) o sus rollizos dieciocho años ( $\neq$ sus dieciocho rollizos años) no puede hacerse, si no es mediante el recurso al significado ya que las clases aparecen aquí superpuestas. Si comparamos

a) las tres primeras páginas /b) las primeras tres páginas
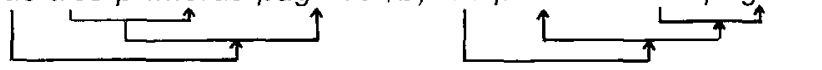

con

c) los fieros marineros coruñeses /d) los marineros coruñeses fieros

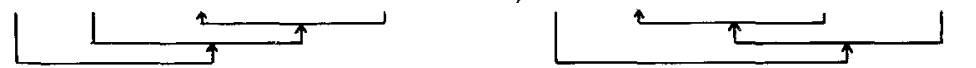

se observa que sólo el último ejemplo es abordable por la teoria anterior, aunque se tengan en cuenta los equilibrios de Stiehm sobre el contraste y la complejidad. Si se cuentan las páginas de 3 en 3 es aceptable las primeras/segundas/últimas tres páginas. Si se cuentan normalmente de una en una es preferible entonces las tres/cuatro/diez primeras páginas (véase la $\varnothing$ primera página), por lo que la relación profunda establecida es diferente. Con tres 1 (cardinal) y tres 2 (cardinal+/frec/) el problema distribucional queda inmediatamente repuesto a su situación normal. En el segundo ejemplo pasa o mismo.

e) sus dieciocho rollizos años $/ \mathrm{f}$ )
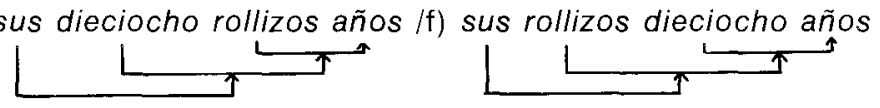

donde en e) se afecta al total de la edad ( $\sim$ «siempre fue rolliza»), pero en f) se indica mucho más probablemente que es «rolliza al cumplir los 18 ». Es decir diecio$\mathrm{cho}_{a}$ (extensión lineal) vs dieciocho ${ }_{b}$ (situación puntual). Pues bien, esta solución no es la típica de $W$. Bull, pero en él ya se advierte algo así cuando afirma (pp. 33-4):

«... the existence of distinct forms for cardinal and ordinal numbers tends to obscure the fact that all cardinal numbers are bivalent, that is, potencially either cardinal or ordinal... un capitulo and capitulo uno".

En este caso, uno $o_{x}$ (cardinal) vs uno (ordinal) es equivalente a decir que un(o) tiene dos valencias. Al mismo tiempo Bull se aferra a la idea de si los adjetivos AS/SA permiten o no la reducción de referencia: los bondadosos leñadores (unos)/(todos) son bondadosos// pero los problemas geométricos (unos)/(todos) son geométricos, 
donde al índice fijo de geométricos 1 habría que oponer el índice doble de bondadoso $_{1}$ bondadoso 2 . Nosotros preferimos considerar un solo ejemplar de bondadoso (nivel sistemático AS/SA), para evitar que se confunda el ejemplo anterior con los que acarrean diferencias de significado: un nuevo 2 coche $\neq u n$ coche nuevo 1.

$\mathrm{Si}$ hacemos un adelanto en la discusión futura tenemos que convenir en que bondadosos es sólo aparentemente diverso en el contexto que nos ocupa: el adjetivo puede mantener o reducir la diferencia, pero en ningún caso cambiarla, como es opinión generalizada. Con ello se aprecia que un distinto comportamiento sintáctico:

g) los bondadosos leñadores $/ \mathrm{h}$ ) los leñadores bondadosos

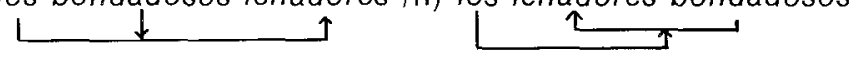

no siempre es prueba suficiente de cambio de significado. Quizá por esto, la prometedora teoría de valencias se ha difuminado en estudios e incluso diccionarios de escaso valor semántico (Pelzing, 1981; Sommerfeldt-Schreiber, 1983, etc.).

\section{La posición del adjetivo en el generativismo}

El generativismo, haciéndose eco de problemas de referencia como los citados, asocia las oraciones de relativo explicativas al orden AS y las especificativas al orden SA y con ello cree tener resuelto el problema, pero como señala Bull en otro trabajo suyo (Bull, 1950) aparte de los adjetivos restringidos a AS y a SA, Ios adjetivos bivalentes se subdividen al menos en siete subclases más según el significado sea idéntico o difiera, etc. Sin embargo, el generativismo no ha dado jamás una explicación adecuada de estos fenómenos ni siquiera en sus soluciones más prudentes. M. Luján, por ejemplo, hace que adjetivos como natal (*su natal ciudad ( ${ }^{*}$ natalmente/su ciudad natal) o francés ( ${ }^{\star}$ francés vino/ ${ }^{*} e l$ vino es francés) se deriven de nombres o que cansada lo haga de un adverbio (la maestra *es/llegó cansada). Pero también presunto se deriva de un adverbio según esta autora a pesar de el presunto asesino (pero */a cansada maestra) *el asesino está presunto (pero la maestra está cansada), etc. En cuanto a los adjetivos centrales el generativismo los produce transformativamente desde oraciones atributivas, aunque el problema se agrava con la doble cópula del español: la niña es/está triste $\rightarrow$ la niña que es/que está triste $\rightarrow$ /a triste niña (es)//a niña triste (es/está) pero el otoño es triste/*está $\rightarrow$ el triste otoñolel otoño triste, etc., etc.

Con ello, la única solución para justificar la doble cópula es considerar ambiguas las estructuras de adjunción, aunque trabajos más documentados como el de Zierer (1974) donde se aprecian casos de modificación del sustantivo (un pequeño estudio 1 vs un estudio 2 pequeño - trabajos vs taller), del adjetivo (una carta simple $\neq$ una simple carta $\left({ }^{*} / a\right.$ carta es simple)) o de ambos (el Año nuevo $\left(1 .^{\circ}\right.$ enero) $\neq e$ el nuevo año (el venidero)), etc., desaconsejan un planteamiento que presenta incalculables consecuencias negativas e insolubles problemas de referencia (Bolinger, 1967) (Cfr. hombre feroz (particular) vs el hombre es feroz (genérico como el hombre es mortal)).

Si se parte del enfoque escindido del generativismo ortodoxo, la Semántica Generativa, que ha ocupado parte de las especulaciones de esta escuela desde la 2 a $^{\text {a }}$ 
mitad de la década de los 60 , tampoco hay mejores resultados. ¿Cómo explicar un adjetivo como lactante en sintagmas tan contradictorios como madres lactantes/bebés lactantes, por ejemplo? Tampoco puede hacerlo la otra rama disidente, la Teoria de los Casos (Fillmore, 1968) que explicaría ambos sintagmas con idéntico entorno casual (A-O) cuando las paráfrasis son realmente conversas: «la madre da leche»-«el bebé toma leche», a pesar de que este enfoque sea útil para otros muchos casos: discursos presidenciales $1(\mathrm{O}-\mathrm{A})$, pero elecciones presidenciales $2(\mathrm{O}-\mathrm{B})$, etc.

\section{Otros enfoques}

Aproximaciones más modernas no son más felices en los planteamientos. Nadie puede pretender que la solución pragmática que se dé a valiente deba ser igual en una mujer valiente y una mosca valiente o que un astronauta cobarde sea realmente una persona cobarde, lo que se plantea como un problema de sincategorematicidad de algunos adjetivos (salsa verde $\rightarrow$ algo verde, pero ratón grande $\rightarrow$ animal grande). Lo mismo ocurre con la modalidad (una estrella lejana $\rightarrow$ una estrella, pero presunto asesino $\rightarrow$ un asesino). Con estos dos obstáculos los lógicos montaguianos encuentran graves problemas para el enfoque intensional que propugnan (Montague, 1977).

\section{SEGUNDA PARTE}

Tras ponderar toda la gama de argumentos expuestos más arriba, no queda sino aplicar la teoría con que se define y apoya la Pragmática Léxica ${ }^{11}$. Esta, que se basa en una topología inicial, tiene por objetivo el convertirse en la síntesis superadora de los resultados contrapuestos que ya hemos analizado.

\section{Tratamiento desde la lógica clásica}

Hasta ahora ha sido obviado un problema básico: el cambio de significado del adjetivo según su posición en el sintagma nominal. Este tema es, sin embargo, el caballo de batalla de la mayoría de los autores que han profundizado en él y también el que ha llevado a muchos a falsearlo en el intento de buscar una solución coherente para el mismo. Pero ésta no existe —afortunadamente, diríamos nosotros- porque son forzosamente varias las propuestas válidas que se presentan al investigador. Así, por ejemplo, el tópico para a) un pobre hombre/b) un hombre pobre, si se desglosa desde el «modus» y el «dictum» de la lógica clásica, admite dos interpretaciones diferentes:

11 En líneas generales, la $\mathrm{PL}$ responde a una estructura matemática - no desarrollada aquí- consistente en conjuntos de abiertos y cerrados, donde las propias palabras del léxico se describen metalingüisticamente a si mismas o mediante otros abiertos del lenguaje. 
a) MODUS:<yo afirmo>+DICTUM: hay un hombre+el hombre es pobre

Presentador identif.+calificado

b) MODUS:<yo me compadezco de él>+DICTUM: hay un hombre $+\varnothing(?)$ causas (?) (identif.) presentador

En a) la pobreza es objetiva, explícita: bienes económicos (función representativa o simbolo). En b) el E. del mensaje se incluye en él subjetivando por causas no citadas la calificación del nombre (función expresiva o sintoma) ${ }^{12}$. Según esto, existirá pobre $_{1}$ (/-//Posesión/) y pobre 2 (/+//Compasión/) como se comprueba incluso en sus peculiaridades morfológicas: pobre $1=$ pobrísimo, pobretón pero pobre $2=$ pobrecillo, pobrete, o semánticas: pobre $1 / r i c o, p o b r e_{2} / \varnothing$. Esto no ocurre, por ejemplo, en una deliciosa muchachaluna muchacha deliciosa (siempre subjetivos) o un alto edificiolun edificio alto (siempre objetivos).

Un caso diferente en cuanto a la solución, pero también típico, es el de c) cierta noticia/ d) noticia cierta, que ha solido interpretarse a través de la oposición «indefinido»/«definido», pero más bien parece remitir a una formalización modal. Sea:

1) Corre cierta noticia sobre Juan

2) Corre una noticia cierta sobre Juan

En el caso 1) el adjetivo cierto, sólo supone una indefinición del sujeto y el objeto del «dictum», pero no del «modus» que es una aserción del verbo: Yo digo que se dice. En 2) el adjetivo cierto 2 se comporta de un modo idéntico con respecto al "dictum», pero a diferencia de cierto ${ }_{1}$ en el «modus» se hace la aserción sobre el objeto y no sobre toda la oración, lo que revela que cierto 2 es un adjetivo modal (cierto 2 /falso) y cierto 1 no lo es. O sea:

c) DICTUM: $X$ (se dice algo sobre Juan)+MODUS: $<Y$ o comento $X>$

d) DICTUM: $X$ (se dice algo sobre Juan)+MODUS: $<Y_{0}$ digo QUE $X_{0}$ es Verdadero $>=\left\langle Y_{0}\right.$ aseguro $\left.X_{0}\right\rangle$

Sin embargo, en ambos casos puede permanecer la idea de "definido»:

1. $\left.{ }^{\circ}\right)$ Corre cierta noticia sobre Juan: que Juan se ha ido (V V F) (cierto ( .

$\left.2 .^{\circ}\right)$ Corre una noticia cierta sobre Juan: que Juan se ha ido (V) (cierto $)$. Como expresa clarividentemente $\mathrm{M}^{\text {a }}$ Moliner (s.v. cierto), cierto antepuesto indica precisamente «determinado" aunque la cosa puede ser desconocida por el que habla, por el que escucha o por ambos. En cierto 2 el E., sin embargo, conoce la verdad. Los subíndices son reveladores al respecto ${ }^{13}$.

\section{Tratamiento liminar}

Desde el enfoque de la teoría liminar los adjetivos anteriores se originan en un mismo punto de EE o «estructura enunciativa». Dado:

$\left.\omega^{\prime(1)}\left[\Omega^{(2)}: \omega^{(3)} C^{\left(3^{\prime}\right)} \bar{\omega}^{\left(3^{\prime \prime}\right)}\right): \Omega^{(4)}\right]$ (López Garcia, 1980: 186 ss.)

12 Esto se sabe con exactitud desde que Benveniste (1966: 82-91) demostró espléndidamente la participación del emisor en el mensaje. Cfr. «El aspecto formal de la enunciación», op. cit.

13 Son éstos los habituales de la Lógica para las expresiones definidas e indefinidas Bierwisch (1976: 105-139). 
(1) define los elementos performativos independientemente de la categoría en que se concreten. Cuando se trata de la estructura oracional, los adjetivos correspondientes se ubican en EP (Es posible que vengas); sin embargo, en la estructura faseológica, cuyo ámbito estamos estudiando, el adjetivo pasa a ocupar un nudo en el orden lineal similar al de los modales o la negación (El o «estructura lineal»). Pero este orden es relativo: en el caso de cierta noticia/noticia cierta el adjetivo ocupa la posposición al constituirse en anteposición un cuantificador indefinido con posibilidad de rellenar el nudo/. Es decir:
$\omega^{(5)}$
$\rho^{(b)}$
$\bar{\omega}^{(7)}$
una ciertaz
(noticia) (Cfr. */a cierta noticia)

Obsérvese que en $/^{(0)}$ puede actuar la negación y el adjetivo que niega al sustantivo siguiente (una falsa mujer-no es mujer), así como la afirmación (una verdadera mujer-una mujer). En el caso que se analiza, sólo el sintagma siguiente $\left(\mathrm{O}_{+1}\right)$ manifestado fraseológicamente a partir de $\theta$ permitirá rellenar un nudo con ciertor:

(O) $\bar{c} \ldots\left(\mathrm{O}_{+1}\right) /($ o)

la (noticia) cierta 1 (Cfr. una noticia cierta/la noticia cierta)

Esto se traduce obligatoriamente en una «incidencia» en el ámbito fraseológico cuya estructura

$f\left(x(\omega) « \ldots y^{i} \ldots y^{j} \ldots »(\bar{\omega} / \ldots)\right)$ (López García, 1983a: 67-109)

responde a lo siguiente: dado $\mathrm{x}(\omega)$ (sustantivo nuclear), el adjetivo cierto 1 forzado por la elección paradigmática de cierto $_{2}$ debe desplazarse de la frecuente ubicación que le correspondería a la posposición:

$y(\bar{\omega})-x(\omega) \rightarrow x(\omega)-y(\bar{\omega})($ para cierta 1 noticia $\rightarrow$ noticia cierta 1$)$

Lo mismo ocurriría en una verdadera ${ }_{2}$ joya $_{\mathrm{p}}$ luna joya ${ }_{1}$ verdadera ${ }_{1}$, etc. En el par un hombre pobre/un pobre hombre es la presión del E. como prenuclear en EE $\left(\Omega^{(2)}\right)$ quien obliga al desplazamiento del adjetivo objetivo a SA. (tal es el caso de un gran emperador/la alta sociedad frente a una institución grande/un emperador alto, etc.). En ambos casos, el nivel fraseológico queda condicionado por fuerzas exteriores a la frase en sí, pero cuando en la comunicación los elementos modales o de cualquier otro matiz externo quedan en segundo plano, se puede reponer la teoría fraseológica liminar en toda su extensión (Cfr: un edificio alto/un alto rascacielos), cuya estructura es

$f\left(x(\omega), \ll \ldots y^{\mathrm{i}} \ldots \mathrm{y}^{\mathrm{j}} \ldots \gg(\bar{\omega} / \ldots)\right)-\mathrm{f}\left(\mathrm{x}(\omega), \ll \ldots \mathrm{y}^{\mathrm{i}} \ldots \mathrm{y}^{\mathrm{j}} \ldots{ }_{\text {(un }) \text { edificio }}{\underset{\text { alto }}{\downarrow}(\bar{\omega} / \ldots))}_{\text {un alto rascacielos }}^{\downarrow}\right.$

La interpretación no puede ser otra que ésta de inspiración praguense: el adjetivo pospuesto "es especificativo porque se predica de un núcleo», pero el ante- 
puesto «es explicativo porque adelantado...rige un núcleo incluyéndolo como subconjunto suyo» (p. 102). Si dejamos de lado por el momento el problema de la referencia, responsable inmediata de la clasificación de los adjetivos en explicativos y especificativos, el gráfico $A$, en el que se ha de suponer un predominio lógico del sustantivo ${ }^{14}$, se simplifica en $B$ :

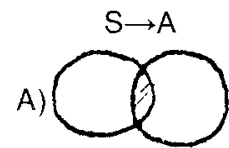

Sust +Adj

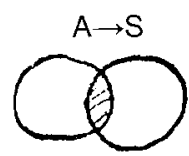

Adj+Sust
B)

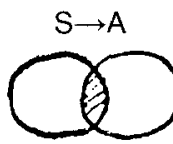

Sust + Adj $=$

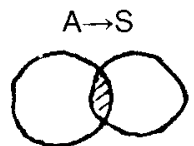

Adj+Sust

Este último debe traducirse como ubicación pura SA/AS: adjetivo específico pospuesto vs sustantivo específico pospuesto que es la más neutral, la más natural de todas las propuestas y la que asume, por tanto, la Pragmática Léxica como argumento de base.

\section{Clasificación pragmático-léxica}

Llegados a este punto debe plantearse cuál debe ser la pretensión de la PL. Esta rama de la lingüística, que se erige en el límite más próximo a la Clausura del lenguaje frente al mundo, es la Topología más gruesa que pretende explicar léxicamente, abarcándolas, cada una de las topologías más particulares que se han comentado en la primera parte. Cfr. este gráfico aclaratorio:

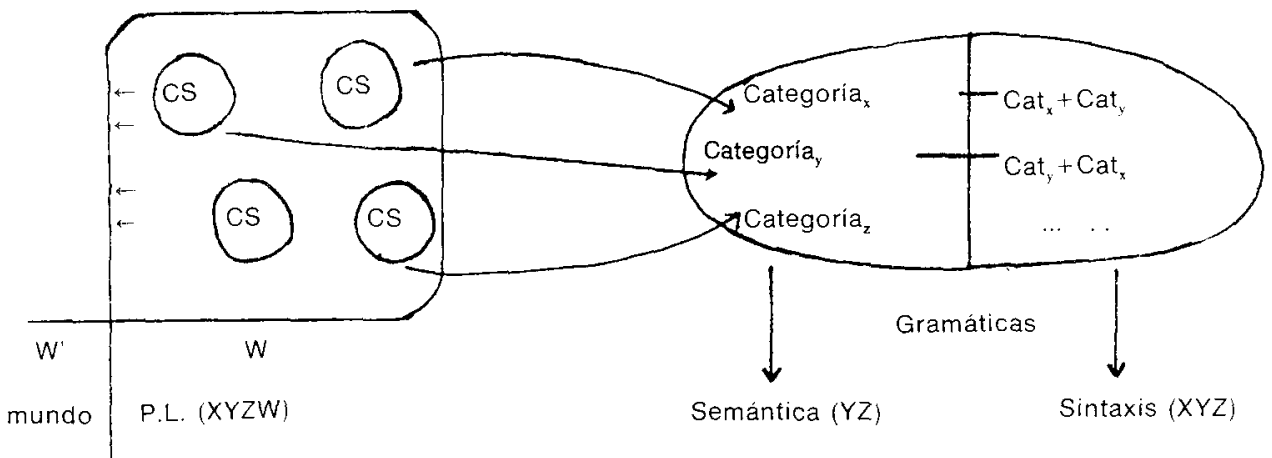

Esto quiere decir que, mientras no se acote previamente el C.S. al que pertenece el adjetivo y el sustantivo que entran en relación, no es posible intentar una solución generalizada para el problema de la posición del adjetivo. He aquí, para terminar, cuáles pueden ser las posibilidades más frecuentes:

1. ${ }^{\circ}$ Adjetivos de proyección primitiva

1a1) Regulares: el adjetivo y el sustantivo son homoléxicos. Entonces se dice 
que pertenecen al mismo hipersema y son compatibles ${ }^{15}$. Por ejemplo, dulce (/Material//Sensorial/) y vino (/Mat//Liquido/). El resultado se traduce en una frase denotativa con doble posibilidad: vino dulce/dulce vino. Puede decirse entonces que la proyección categorial se realiza al unísono sin que medie traslación. La tendencia es SA:

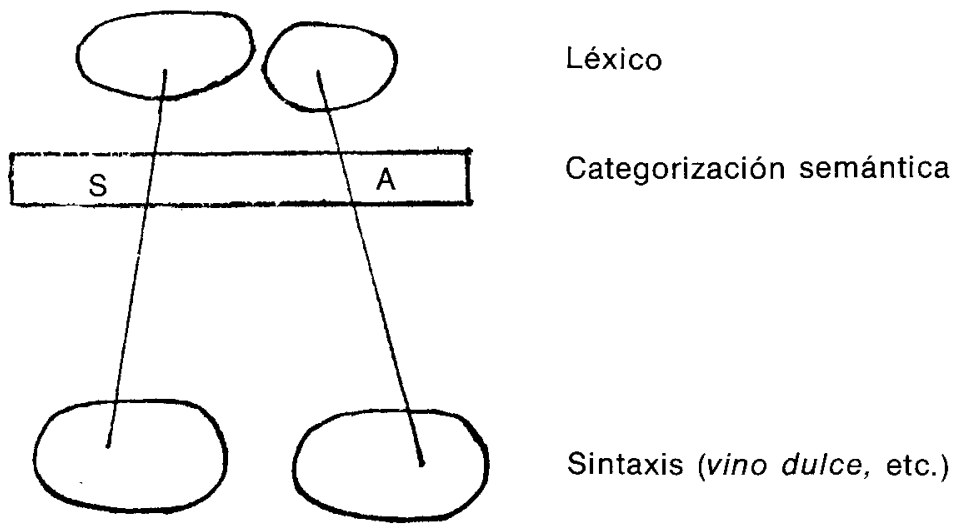

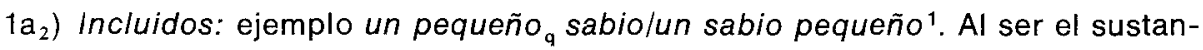
tivo hiposémico de $/ \mathrm{Hum} /$, AS se decanta por la connotación psíquica y abstrae del sustantivo el rasgo compatibilizador (es la «modificación de referencia» de D. Bolinger y la referencia a "concreto» —adj. de un solo individuo- de L. Waugh). En SA, el adjetivo físico denotativo exige, también por compatibilidad semántica, actuar sobre la extensión física del género: sabioe/Hum/ (es la "modificación del referente» de D. Bolinger o la referencia a adjetivos «generales»-adj. de clase- de $L$. Waugh).

1b) Contaminados: el adjetivo y el sustantivo son homoléxicos, pero su compatibilidad es sólo parcialmente coordinable. Por ejemplo: un gran hombre/un hombre grande. En esta circunstancia, la posición marcada cede su puesto para que el adjetivo lo ocupe la solución divergente. Un gran ${ }_{\mathrm{q}}$ hombre//un hombre grande (alto, $_{\mathrm{q}}$ etc.)/un hombre grande ${ }_{\mathbf{q}}$ (extraordinario). En este caso se aprecia que grande, es «N/Dimensión//f. \% y grande ${ }_{\mathrm{q}}$, «>N/ps. $\%$ " por lo que la pérdida de un sema se realiza tanto en AS como en SA. Con ello se invalida la tesis de Ch. Bally y la de $H$. Weinrich. Por lo demás, en AS el Emisor participa, pero en SA no lo hace, de ahí el matiz particularista de Manolo es un gran muchacho, etc.

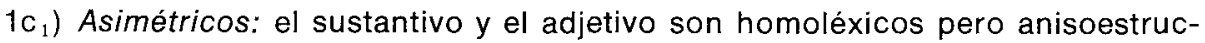
turales. Su compatibilidad se resuelve en distribución complementaria: una pobre ${ }_{2}$ mujer/una mujer pobre ${ }_{1}$. La relación dicotómica equivale, como se sabe, a E. subjetivo vs $\mathrm{E}$. objetivo.

$1 c_{2}$ ) Indeterminados: el sustantivo y el adjetivo son homoléxicos también, pero

15 Para esta terminología. Calvo (1985). Mientras que los semas funcionan en un hipotético nivel cero, los sinónimos parten de él hacia sutilidades mayores que se pierden en la acepción (hiposemas). En el orden saliente son los rasgos de significado, próximos a la estructura lingüistica del mundo, los que se designan como hipersemas. 
su implicación es sólo aparente, ya que de hecho son también dos los adjetivos en juego. Ejemplo, un nuevo ${ }_{2}$ submarino/un submarino nuevo ${ }_{1}$, en donde nuevo ${ }_{1}$ es «-t//Intrínseco/" y nuevo ${ }_{2}$ "/-t//Extrínseco/". Este caso es instructivo. La diferencia por posición se produce solamente cuando el adjetivo entra en relación con sustantivos /Material/. No obstante, como viejo ${ }_{2} /$ nuevo $_{2}$ también pueden darse con /-Mt/ -a diferencia de viejo ${ }_{1} /$ nuevo $_{1}$-, no es preciso recurrir, en este último caso, a la posición como elemento terminal de desambiguación: ésta se produce ya en la EP y el orden de las palabras queda libre como en $a_{1}$ ). Ejemplo: la nueva $a_{2}$ demostración/la demostración nueva ${ }_{2} /$ /las nuevas ${ }_{2}$ tecnologias/las tecnologias nuevas ${ }_{2}$, etc. En este mismo orden de cosas, cuando viejo/nuevo prefieren una diversificación más temprana originada directamente en la estructura pragmático-léxica, se desdoblan en antiguo/moderno con lo cual la potencialidad desambiguadora se mantiene en su totalidad. Por el contrario, si es la compatibilidad semántico-clasémica la que interesa, la aplicación a / Hum/ nos proporciona el par viejo ${ }_{3} / j o v e n$ (nuevo 3 ).

1d) Restringidos: son también homoléxicos y presentan dos modalidades distintas. $d_{1}$ ) $O$ antepuestos, que por su proximidad al determinante son siempre AS: la mera inclusión/*la inclusión mera y $\mathrm{d}_{2}$ ) o pospuestos, los que por su capacidad restrictiva fija (adj. de relación o pseudoadjetivos) permanecen siempre en SA: el planteamiento matemático, el reino vegetal, etc. En ambos se cumple la ley semántica enunciada en la $1 .^{a}$ parte, pues AS tiende a la identidad del nombre consigo mismo - adj. identificativos de medida intrínseca- y SA a la reducción obligatoria de su referencia - adj. clasificadores-.

1i) Irregulares: el adjetivo y el sustantivo son heteroléxicos. En esta circunstancia se prevén al menos dos posibilidades:

$1 i_{1}$ ) Coordinables: pertenecen a distintos hipersemas y su incompatibilidad es coordinable. Por ejemplo, du/ce (/Mat//Sens/) y sueño (/-Mat//f. $\%$ ): un sueño dulce un dulce sueño: Al ser la apreciación subjetiva y de carácter connotativo se tiende a la anteposición, pero factores variables (véase más arriba) permitirán también SA. En este caso dulce ${ }_{1}$ se transforma en dulce ${ }_{\mathrm{q}}$ por referencia a $/ \mathrm{Hum} / \mathrm{y} / \mathrm{ps} . \%$ dulce mujer/mujer dulce, etc.

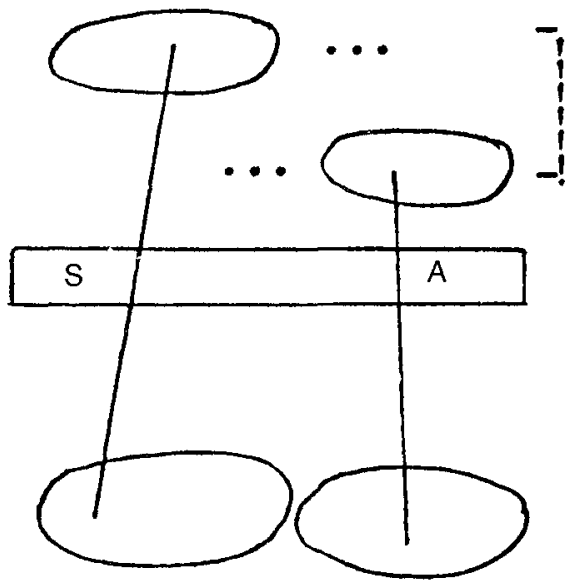

Léxico

Categorización semántica

Sintaxis (du/ce mujer/mujer dulce, etc.) 
$1 i_{2}$ ) Incoordinables. Pertenecen a distintos hiposemas y sólo existen teóricamente. Ejemplo, *gusano criptógamo, donde el sema /Anim/ del $10^{\circ}$ es incompatible con el sema /Vegetal/ del $2 .^{\circ}$ De darse, en el discurso pasan a connotar como $i_{1}$ ).

\section{$2^{\circ}{ }^{\circ}$ Adjetivos de proyección sintáctico-categorial}

Puede darse también una serie de supuestos.

2a) Dos sustantivos en contacto apositivo tienden a estructurarse como en el orden no marcado SA. Entonces el $2 .^{\circ}$ traspone su categoría a A; perro lobo:

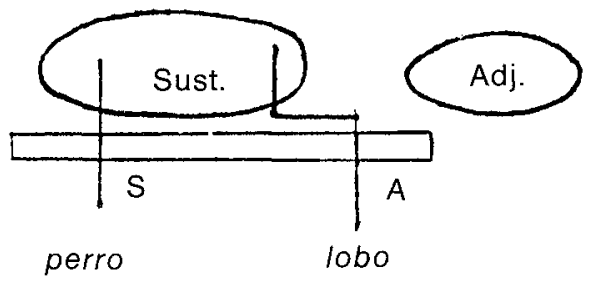

Este se traduce siempre en un orden fijo por prevalencia absoluta del primer sustantivo sobre el segundo: perro lobo $\rightarrow$ perro, etc.

2b) El sustantivo, en contacto con un adjetivo, modifica a éste en posición marcada con resultado final adjetivo. En tal caso, el sustantivo se traslada de categoria a A: azul cielo.

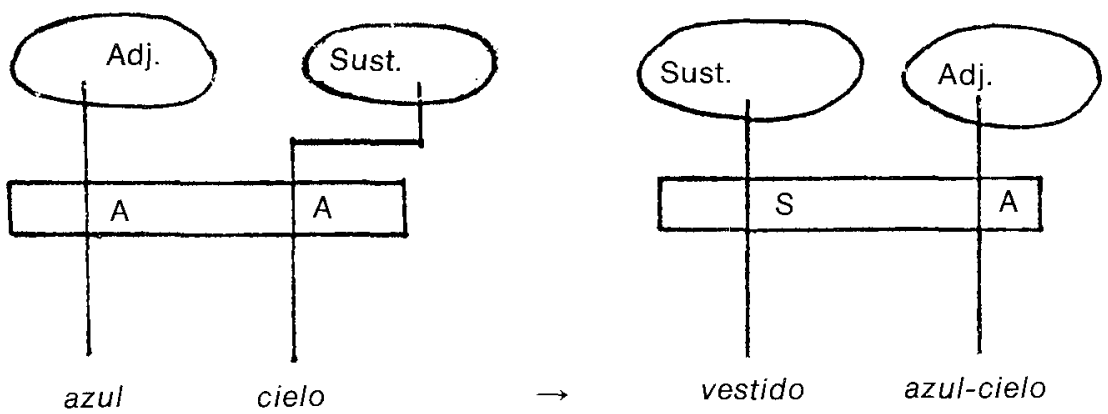

Este sintagma equivale al orden fijado y directo de la traslación cruzada de L. Tesnière (el azul del cielo $\rightarrow a z u l$ cielo), pero con resultados distintos: azul cielo $\rightarrow$ cielo/azul cielo $\rightarrow$ azul.

2c) Dado un adjetivo en contacto con otro adjetivo, por ser el orden no marcado el SA, el que se ubica en primer lugar se sustantiva. Esto ocurre preferentemente con categorías semánticas no bien perfiladas, como en el ejemplo un sabio francés/un francés sabio, donde se observa la conveniencia de una derivación morfológica previa: 


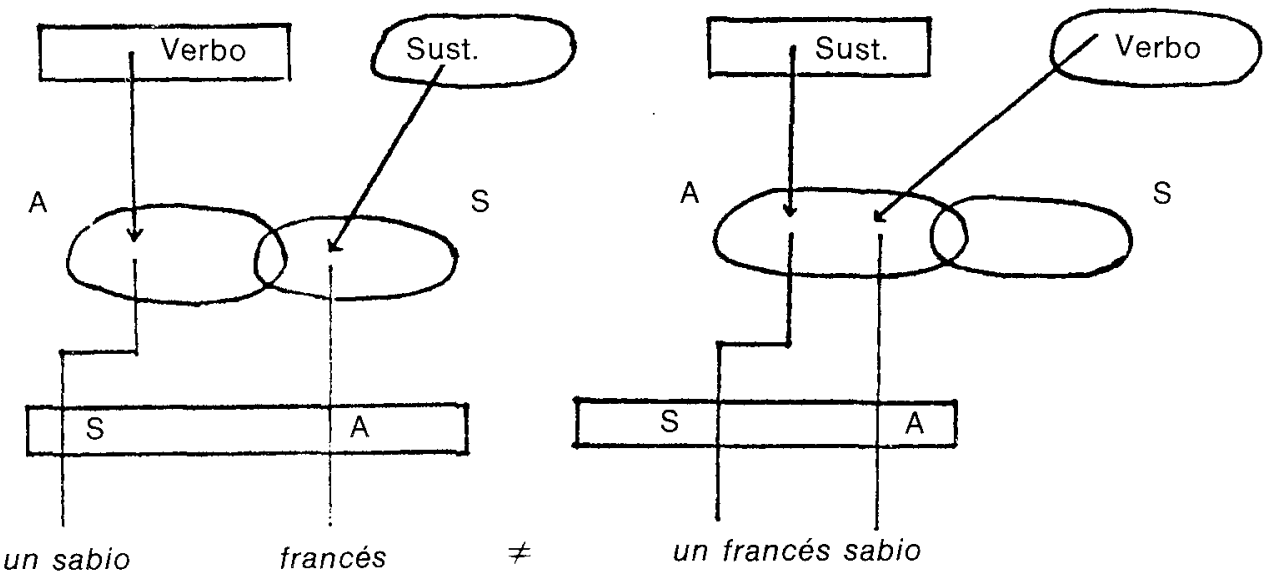

Obviamente las posibilidades están limitadas y no es posible modificar el orden significativo.

\section{Adjetivos de proyección sintáctico-fonosémica}

3a) Un adjetivo sin modificar su significado originario adopta anteposición enfática fijada. Ejemplo, Magnífico piso! (Sdo. A=Sdo. A). Entonación

3b) Un adjetivo, modificando su sentido originario por vías de ironía, adopta una anteposición enfática fijada con una cadencia menos pronunciada que en $3 a$ ): ;Bonita escena!/iDichoso pueblo! (Sdo. $\mathrm{A}=\overline{\mathrm{A}})$. Entonación

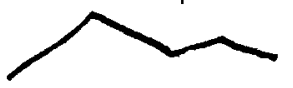

\section{Conclusiones}

1. ${ }^{\text {) }}$ La clasificación que acabamos de hacer permite situar en su justo punto las opiniones reseñadas en la primera parte. Por ejemplo, la dicotomía explic./especif. de A. Bello sirve incluso para casos de aparente neutralización (horrible accidenteaccidente horrible), pero no para los mismos cuando la referencia convierte en especificativo el orden AS y el SA. Por esta causa, nuestro sistema incluye, ya en $1 a_{q}$ ), al suyo. En la posición incide también el orden comunicativo tema/rema, el contexto y los criterios de referencia o presuposición, que también se justifican teóricamente en la misma base pragmático-léxica que, por definición, ası'me AS y SA como compuestos explicativos en $\left.1 a_{2}\right), 1 i_{1}$ ), etc.

La dicotomía subjetivo/objetivo sólo puede aplicarse a $1 c_{1}$ ) que es el único supuesto que la G.L. no explica desde sus estucturas fraseológicas, aunque puede deducirse desde el El correspondiente.

La diversificación síntesis/análisis se aprecia ya en la $1 a_{1}$ ) equivaliendo la primera a $S$ y la segunda a $S \cap A$ desde la perspectiva de $S$ y $A$ y a $A \cap S$ respectiva- 
mente desde la perspectiva de A. En ambos casos la intensión se mantiene o se amplía a costa de la extensión que se mantiene o reduce consecutivamente.

La relación morfema/lexema se observa o distingue en 1b) aunque, curiosamente, no se ciñe a las tesis de Bally.

Por lo demás, la explicación distribucional es sólo un pálido reflejo de las múltiples fuerzas incidentes en el orden final que, sin embargo, con tanta sencillez parece explicar la P.L.

$\left.2^{2}{ }^{a}\right)$ El sustantivo y el adjetivo son léxicamente necesarios y las dependencias entre ellos mutuas. A pesar de esto, la tendencia general SA muestra que el sustantivo es nuclear como ocurre en $1 c_{2}$ ), en $2 a$ ) y en $2 c$ ). No obstante $2 b$ ) es la excepción que se apoya en la mayor fuerza del adjetivo en determinadas construcciones y que culmina en 3a) y 3b): ;Magnifico piso! $\rightarrow$ iMagnifico!l, pero $\rightarrow{ }^{*}$ iPiso! En todo caso se deduce que las apariciones rectas difieren de las oblicuas o connotadas en todo contacto $S / A$, de modo que la sustancia es la que obliga constantemente a la modificación de la cualidad. Unos y otros fenómenos tienen cabida en la P.L.

3. ${ }^{a}$ ) Cuando no se produce la diversificación léxica en el orden primero (C.S.), si tampoco se produce en el morfológico: triste ${ }_{2}$ triste $_{1}$ (una triste mujer/una mujer triste, pero hombre grueso/hombre grosero) será el orden lineal el que refleje definitivamente las diferencias de EP. Es posible que sea ésta misma la que realice la

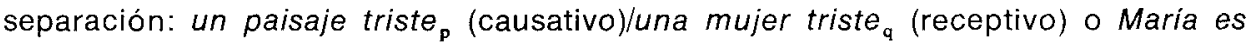
dispuesta ${ }_{\mathrm{q}} /$ Maria está dispuesta ${ }_{1}$ (ser/estar). También puede hacerlo la ES: sus rollizos 18 años/sus 18 rollizos años, etc.

$\left.4 .^{a}\right)$ En contacto con sustantivos humanos principalmente, la compatibilidad léxica puede exigir que se recurra al género o a la especie para determinar el significado. Entonces, las dos categorias en liza sufren desplazamientos: un feliz poeta/un poeta feliz, pero un feliz hallazgo un hallazgo feliz.

$\left.5 .^{2}\right)$ Todos los ejemplos que registra la literatura sobre el tema pueden explicarse a partir de las estructuras pragmático-léxicas. He aquí, como complemento, algunos de ellos: una pura ilusión/una ilusión pural/un simple camaradalun camarada simple//la única ocasión/la ocasión únical/la propia decisión/la decisión propia, etc. En todos ellos AS remite a un adjetivo con valor de/Unidad/. En posposición el significado es variable. De aquí la opinión de Ch. Bally de que los cuantificadores anteceden al nombre, pero este hecho no se produce siempre de igual manera. Asi, en medio hombre/hombre medio el valor de cantidad aparece en ambas posiciones, aunque con significado distinto: medio $(=1 / 2)$ vs medio ( $=\mathrm{N}$ o lugar medio). Curiosamente, además, al tratarse de un cuantificador puro la objetividad es mayor en AS. En viejos amigos/amigos viejos la diferencia de cuantificación no es apreciable fuera de la polaridad inherente a todo adjetivo libre AS/SA, aun tratándose del tipo $1 \mathrm{a}_{2}$ ). Cfr. viejo 1 vs joven/viejo ${ }_{2}$ vs nuevo: dos jóvenes amigos $\sim$ dos amigos jóvenes, etc.

6. $\left.{ }^{a}\right)$ Cuando un adjetivo con un solo significante puede tener en abstracto un conjunto de significados, realizará unos u otros según el sustantivo adjunto: un simple $_{2}$ picap/eitos/un picapleitos simple ${ }_{1} /$ un simple ${ }_{4}$ problema/un problema simple ${ }_{3}$, etc. Entonces es justificable que la polisemia se resuelva en una independencia relativa mayor: la homonimia. Se trata, en definitiva, de que los adjetivos se consideren como unidades léxicas diferentes. Apréciese que con tal argumento la taxonomía original queda reducida en alto grado. 
$\left.7 .^{a}\right)$ Quedaria también justificada la dicotomía extrínsecolintrínseco no formulada aún por nadie en estos términos. Así, macizo/hueco se oponen a lleno/vacio en que los primeros se refieren a la materia propia, mientras que los segundos se decantan hacia materia diferente: Un vaso lleno $D E$ agua/Una sortija maciza, etc. Como los adjetivos extrínsecos suelen ser transitivos no deben anteponerse: *el lleno vaso, pero la maciza joya.

8. $\left.{ }^{a}\right)$ La explicación liminar de ser/estar para SA/AS vs SA: el suelo *es/está huecol/*el hueco suelo, el tacto de su piel es suave//la piel suave/la suave piel (López García, 1983a) se justifica desde el propio liminarismo y también desde la P.L.: la tendencia a la ubicación del sustantivo en primer lugar es evidente, sobre todo, cuando el adjetivo revela un estado parcial (estar) frente a un estado total (ser) en la manifestación de la cualidad. La relación con las conclusiones del epígrafe $7 .^{\circ}$ es obvia, ya que ser es Proc. puro, pero estar es la adición del binomio formado por Proc. +Result. (léase nudo+lo que va después del nudo).

\section{Bibliografía}

Alarcos, E. (1970), Estudios de Gramática funcional del español, Madrid, Gredos. Alcina J. y Blecua, J. M. (1975), Gramática española, Barcelona, Ariel.

Bally Ch. (1965), Linguistique générale et linguistique français, Berne, Ed. Francke. Bartoš, L. (1978), "Notas a la clasificación del adjetivo", Estudios ofrecidos a $E$. Alarcos Llorach, t. 2, Universidad de Oviedo, pp. 45-60.

Bello, A. (1981), Gramática de la lengua castellana, ed. de R. Trujillo, Aula de Cultura de Tenerife.

Benveniste, E. (1966), «La phrase nominal», Problèmes de Linguistique générale, Paris, Galimard, pp. 151-168.

Bierwisch, M. (1976), “On classifying semantic features», S. y S. de la G. G. II, ed. V. S. de Zavala, Madrid, Alianza, pp. 105-139.

Blommfield, L. (1933), Lenguaje, Universidad de San Marcos, 1964.

Bull, W. E. (1950), "Spanish adjective position: present rules and theories", Hispania XXXIII, pp. 297-303.

- (1954), "Spanish adjective position: the theory of valence classes", Hispania XXXVII, pp. 32-38.

Calvo, J. (1985), «Topología y semántica: fundamentos para una Pragmática Léxica», Cuadernos de Filología I, 3, pp. 159-211. SLH, IV, Valencia, e.p.

Fernández Ramírez, S. (1950), Gramática Española, t. I, Madrid, Rev. de Occidente. Fillmore, Ch. J. (1968), «The case for case», Universals in Linguistic Theory, N. York, Ed. Bach y Harms, pp. 1-88.

Gili Gaya, S. (1973), Curso superior de Sintaxis española, Barcelona, Vox.

Guillaume, G. (1971), Leçons de Linguistique de G. G. (1948-9), Québec, Les Presses de l'Université de Laval.

- (1973), Langage et science du langage, Paris, pp. 157-166.

Halliday M. A. K. (1967-8), «Notes on transitivity and theme in English, Journal of Linguistics, pp. 37-81; 3, 2, pp. 199-244 y 4, 2, pp. 179-215.

Hanssen, F. (1945), Gramática histórica de la lengua castellana, B. Aires, El Ateneo. Harris, Z. S. (1951), Structural Linguistics, The Univ. of Chicago Press (1974). 
Hjelmslev, L. (1972), "El verbo y la frase nominal», Ensayos lingüisticos, Madrid, Gredos, pp. 218-253.

Hockett, Ch. (1971), Curso de Lingüistica moderna, B. Aires, Eudeba.

Jakobson, R. (1975), Ensayos de Lingüistica General, Barcelona, Seix Barral.

Jespersen, O. (1975), La Filosofía de la gramática, Barcelona, Anagrama.

Lamíquiz, O. (1975), Lingüística española, Universidad de Sevilla.

Lenz, R. (1935), La oración y sus partes, Madrid.

López García (1980), Para una Gramática liminar, Madrid, Cátedra.

-- (1983a), «El adjetivo, el problema de «ser/estar» y la atribución», Estudios de Lingüistica española, Barcelona, Anagrama, pp. 67-109.

- (1983b), «La comparación en español...», Serta Philologica a F. Lázaro Carreter, Madrid, Cátedra, pp. 315-327.

Luján, M. (1980), Sintaxis y semántica del adjetivo, Madrid, Cátedra.

Marcos, F. (1980), Curso de Gramática Española, Cincel-Kapelusz.

Martinet, A. (1978), Estudios de Sintaxis funcional, Madrid, Gredos.

Meier, H. (1948), "Adjectivo e adverbio", Ensaios de Filologia romanica, Lisboa, pp. 55-114.

Montague, R. (1977), Ensayos de filosofia formal, Madrid, Alianza.

Nevi, J. N. (1973), "Where do all those other adjectives come from?", Papers from the Meeting of Chicago Linguistic Society, pp. 332-345.

Palková, Z. y Palek, B. (1978), «Functional Sentence Perspective and Textlinguistics", Current Trends in Textlinguistics, N. York, pp. 212-227.

Pelzing, E. (1981), Das attributive Adjektiv des Spanischen: Stellenvert und Stellung, Frankfurt am Main, Lang.

Pottier, B. (1968), Presentación de la Lingüistica, Madrid, Alcalá.

R.A.E. (1973), Esbozo de una nueva gramática de la lengua castellana, Madrid, Espasa Calpe.

Reiner, E. (1968), La place de l'adjectif épithète en français, Wien, Univ. Verlag.

Ringo, E. (1954), "The position of the noun modifier in Colloquial Spanish», Illinois Studies in L. and Lit. Vol. 38, Urbana.

Rojo, G. (1975), «Sobre la coordinación de adjetivos en la frase nominal y cuestiones conexas", Verba, 2, Univ. de Santiago, pp. 193-224.

Salvá, V. (1852), Gramática de la Lengua castellana según ahora se habla, Valencia. Sciarone, B. (1967), "Sur la place de l'adjectif en français», Z.R.P. LXXXII, pp. 583598.

- (1970), La place de l'adjectif en italien moderne, The Hague, Mouton.

Sgall, P. (1972), "Topic, Focus and the ordening of elements of Semantic Representations", Philologica Pragensia, 54, pp. 1-14.

Simón, C. (1979), «El problema de la colocación del adjetivo en castellano», Cuadernos de Filologia II, 1 (SLH), Valencia, pp. 183-198.

Sommerfeldt, K. E. y Schreiber, H. (1983), Wörterbuch zur Valenz und Distribution deutscher Adjektive, Max Niemeyer Verlag.

Stati, S. (1973), "Les traits sémantiques de l'adjectif», Cahiers de Lexicologie, XXIII, 2, pp. 51-61.

Stiehm, B. G. (1975), "Spanish word order in non-sentence constructions» Language, 51,1 , pp. 49-88.

Tesnière, L. (1966), Éléments de sintaxe structurale, Paris, Klincksieck. 
Vendler, Z. (1968), Adjectives and Nominalizations, The Hague, Mouton.

Waugh, L. (1976), "The semantics and paradigmatics of Word Order", Language, 52, 1, pp. 82-107.

-- (1977), A semantic Analysis of Word Order, E. J. Brill, Leyden.

Weinrich, H. (1966), "La place de l'adjectif en français", Vox Romanica, 25, pp. 82-89.

Zierer, E. (1974), The qualifying adjective in Spanish, The Hague, Mouton. 